\title{
Comparative Study between Bupivacaine versus Bupivacaine with Dexmeditomidine in Ultrasound Guided Transversus Abdominis Plane Block for Postoperative Analgesia in Cancer Patients Undergoing Major Pelviabdominal Surgeries
}

\author{
NAHLA N. SHEHAB, M.Sc.; MAIE K. EL-HELALY, M.D.; AYMAN A. GHONEIM, M.D. and \\ GHADA M. NABIH, M.D.
}

The Department of Anesthesia, Pain and Intensive Care, National Cancer Institute, Cairo University

\begin{abstract}
Background: The main contributor to the pain experienced after abdominal surgery is pain from the incision made in the abdominal wall. The Transversus Abdominis Plane (TAP) block is a peripheral nerve block to the nerves supplying the anterior abdominal wall (T6 to L1). The aim of this study was to evaluate the effect of dexmedetomidine as an adjuvant in ultrasound guided TAP block on post-operative analgesia and morphine consumption in patients undergoing major abdominal or pelvic surgeries.
\end{abstract}

Methods: Seventy five patients were randomly enrolled in the study; patients were divided into 3 groups: Bupivacaine group (group TAP, $\mathrm{n}=25$ ) received TAP block with bupivacaine done after skin closure, bupivacaine with dexmedetomidine group (group TAP + Dex, $n=25$ ) received TAP block with dexmedetomidine added to the bupivacaine and intravenous dexmedetomidine group (group TAP + IV-Dex) received TAP block with bupivacaine in addition to intravenous dexmedetomidine.

Results: The mean time to the first rescue analgesic requirement was significantly longer in both group TAP + Dex $(9.8 \pm 2.9)$ hours and group TAP + IV-Dex (10.0 \pm 2.3$)$ hours than in group TAP $(5.7 \pm 1.6)$ hours $(p<0.001)$. Total morphine consumption in the first 24 hours post-operatively was significantly higher in group TAP $(24.3 \pm 3.6) \mathrm{mg}$ than in both group TAP + Dex $(11.8 \pm 3.7) \mathrm{mg}$ and group TAP + IVDex $(11.8 \pm 3.6) \mathrm{mg}(p<0.001)$. Post-operative VAS pain score was higher in group TAP than in group TAP + IV-Dex at 6 and 12 hours but all three groups were comparable at 2, 4 and 24 hours. Patient satisfaction score was significantly lower for group TAP in comparison to the other two groups $\left(p^{<}\right.$ $0.001)$.

Conclusion: Dexmedetomidine whether added to bupivacaine in the TAP block or administered intravenously improved postoperative analgesia with lower total morphine consumption in the first 24 hours post-operative as a part of multimodal analgesia in abdominal and pelvic surgeries.

Correspondence to: Dr. Nahla N. Shehab, The Department of Anesthesia, Pain and Intensive Care, National Cancer Institute, Cairo University
Key Words: Abdominal surgery - TAP block-Dexmedetomidine - Post-operative analgesia.

\section{Introduction}

ACUTE post-operative pain is usually sub optimally treated resulting in adverse effects such as prolonged hospital stay, thromboembolic and pulmonary complications, unnecessary suffering and development of chronic pain. The multimodal approach of pain management, as defined by the American Society of Anesthesiology (ASA) (2012), is administration of two or more drugs that act by different mechanisms via the same route or different routes to provide optimal analgesia [1].

The main contributor to the pain experienced after abdominal surgery is incisional pain from the abdominal wall. The Transversus Abdominis Plane (TAP) block is a peripheral nerve block to the nerves supplying the anterior abdominal wall (T6 to L1). It was first described in 2001 by Rafi as a traditional anatomical technique [2]

The TAP block was found to reduce the need for post-operative opioid consumption, increase the time to first request for further analgesia, and provide more effective pain relief, while decreasing opioid related side effects such as sedation and postoperative nausea and vomiting [3]. The introduction of ultrasound has allowed identifying the correct tissue plane and performing this block under direct visualization with more accurate results [4].

Research to find a better adjuvant in regional anesthesia is ongoing. Alpha ( $\alpha)$-2-adrenergic (AR) agonists are characterized by analgesic and sedative 
actions when used as an adjuvant in regional anesthesia [5]. The addition of dexmedetomidine to local anesthetics or given IV prolongs the duration of sensory block of local anesthetics during peripheral nerve block [6]. Peripheral analgesic effects of dexmedetomidine that aggravate local anesthetics action are mediated by $\alpha 2 \mathrm{~A}-\mathrm{AR}$ receptor binding [7].

Alpha-2-adrenergic receptor agonists have been the center of interest for their sedative, analgesic, perioperative sympatholytic and hemodynamic stabilizing properties [8]. Dexmedetomidine is a highly selective $\alpha 2$-AR agonist with a comparatively high ratio of $\alpha 2 / \alpha 1$ activity (1620:1 as compared to 220:1 for clonidine) that possesses all these properties without causing respiratory depression [6], making it a useful and safe option in various clinical applications [9]

The aim of this study was to compare the conventional ultrasound guided TAP block with bupivacaine and TAP block with dexmeditomidine whether added to the local anesthetic or given intravenously regarding effect on post-operative analgesia, opioid requirement, patient satisfaction and possible side effects.

\section{Patients and Methods}

The study was conducted at the National Cancer Institute (NCI), Cairo University after approval of its Institutional Ethics Committee from May 2014 to April 2016. A written informed consent was taken from the patients undergoing the study. Seventy five cancer patients scheduled for major abdominal or pelvic surgery aged 18-65 years of both sexes and ASA (American Society of Anesthesiology) physical statuses I, II or III were enrolled in this study. Patients were excluded in case of bradycardia or heart block, renal and hepatic impairment, low platelet count and coagulation defects, history of epilepsy, known allergy or hypersensitivity to the used drugs and local or systemic infection. In the holding area, all patients were premedicated with intravenous midazolam $(0.02$ $\mathrm{mg} / \mathrm{kg}$ ). Preoperative medications were given just prior to induction in the form of Ranitidine $(50 \mathrm{mg}$ IV) and metoclopramide (10mg IV). In the operating room patients were continuously monitored with ECG, pulse oximetry and non-invasive automated arterial blood pressure. All patients received standardized anesthesia. Intravenous induction of anesthesia was achieved with propofol $(2 \mathrm{mg} / \mathrm{kg})$, fentanyl $(2 \mathrm{ug} / \mathrm{kg})$, and atracurium $(0.5 \mathrm{mg} / \mathrm{kg})$ to facilitate endotracheal intubation, followed by volume controlled ventilation with $\mathrm{FIO}_{2} 50 \%$.
Upon skin closure, paracetamol at $15 \mathrm{mg} / \mathrm{kg}$ IV was administered and continued every 6 hours in the Post Anesthesia Care Unit (PACU).

Patients were randomly allocated using permuted random blocks method into three equal groups of 25 patients each. At the end of the surgery, bilateral Ultrasound (U/S) guided TAP block was performed in all the groups using ultrasound machine SonoSite M-Turbo. A linear multifrequency $(6-13 \mathrm{MHz})$ transducer was used for scanning. The block was done in the supine position sing a $20 \mathrm{G}$ spinal needle after obtaining sterile conditions and skin preparation where the transducer was placed in a transverse plane above the iliac crest in the region of midaxillary line. After verifying correct position by visualizing shaft of the needle in the correct plane and clear negative suction, $2 \mathrm{ml}$ normal saline were injected to widen the space then Group TAP: Received $30 \mathrm{ml} 0.25 \%$ bupivacaine (max. $3 \mathrm{mg} / \mathrm{kg}$ ) on each side, Group Tap + Dex: Received $30 \mathrm{ml} 0.25 \%$ bupivacaine with $0.5 \mathrm{ug} / \mathrm{kg}$ dexmedetomidine on each side and Group TAP + IV-Dex received $30 \mathrm{ml} 0.25 \%$ bupivacaine on each side in addition to a loading dose of dexmeditomidine $1 \mathrm{ug} / \mathrm{kg}$ i.v. over 20 minutes given during skin closure (approximately 30 minutes before performing the block) followed by an infusion of 0.5 $\mathrm{ug} / \mathrm{kg} / \mathrm{hr}$ continued for 2 hours post-operative.

In PACU and surgical unit, Visual Analogue Scale Score (VAS) was recorded at 2, 4, 6, 12 ans 24 hours post-operative. A VAS score of $\leq 3$ was considered satisfactory pain relief. If patients had inadequate analgesia, supplementary rescue analgesia was given in the form of IV ketorolac $30 \mathrm{mg}$ at VAS $\geq 4$ or morphine $0.1 \mathrm{mg} / \mathrm{kg}$ at $\mathrm{VAS} \geq 6$. The time of first request for rescue analgesic and total morphine requirement in the 24 hours period postoperative was recorded. Post-operative nausea and vomiting was documented according to acategorical scale: 0 none, 1 nausea, 2 vomiting, 3 nausea and vomiting. Patient satisfaction was recorded using Patient Satisfaction Score (PSS) which is a linear scale where 0 means very dissatisfied and 10 means very satisfied [10]. Data was analyzed using SPSS with statistical package Version 17. Quantitative data is expressed as mean and standard deviation or median and range as appropriate. Qualitative data is be expressed as frequency and percentage. Chi-square test or Fisher's exact test was used to examine the relation between qualitative variables. Comparison between quantitative data of the three groups was done using either parametric or nonparametric ANOVA test as appropriate. $p$-value less than 0.05 was considered to be significant. 


\section{Sample size estimation:}

Based on the results obtained from a comparative study on the effect of dexmedetomidine added to bupivacaine intrathecal which found a difference in the VAS between the two groups (spinal anesthesia with or without dexmedetomidine) of 2.4 and a standard deviation of 2.2 [11], a sample of 23 cases in each group would be sufficient to elicit that difference at an alpha level of 0.05 and a power of the test of $95 \%$.

\section{Results}

In this prospective, randomized clinical trial, the three groups were comparable regarding age, sex, and Body Mass Index (BMI). (Table 1) the patients had different types of surgery involving the abdomen and pelvis (Table 2). Hysterectomy was the most frequently performed surgery followed by radical cystectomy and colectomy.

Table (1): Baseline patients' characteristics of the three studied groups.

\begin{tabular}{lcccc}
\hline & $\begin{array}{c}\text { TAP } \\
\mathrm{n}=25\end{array}$ & $\begin{array}{c}\text { TAP + Dex } \\
\mathrm{n}=25\end{array}$ & $\begin{array}{c}\text { TAP + IV-Dex } \\
\mathrm{n}=25\end{array}$ & $\begin{array}{c}p \text { - } \\
\text { value }\end{array}$ \\
\hline - Age (years) & $49.4 \pm 9.1$ & $48.9 \pm 8.0$ & $48.6 \pm 9.7$ & 0.940 \\
- Body mass & $30.7 \pm 3.1$ & $31.0 \pm 2.8$ & $30.5 \pm 3.0$ & 0.811 \\
index (kg/m2) & & & & \\
- Sex: & & & & \\
$\quad \begin{array}{l}\text { Male } \\
\text { Female }\end{array}$ & $9(36.0 \%)$ & $8(32.0 \%)$ & $10(40.0 \%)$ & 0.841 \\
\hline
\end{tabular}

Data are presented as mean $\pm \mathrm{SD}$, or number $(\%)$.

Table (2): Type of surgery performed in the three studied group.

\begin{tabular}{llcl}
\hline & $\begin{array}{c}\text { TAP } \\
\mathrm{n}=25\end{array}$ & $\begin{array}{c}\text { TAP + Dex } \\
\mathrm{n}=25\end{array}$ & $\begin{array}{c}\text { TAP + IV-Dex } \\
\mathrm{n}=25\end{array}$ \\
\hline Hysterectomy & $7(28 \%)$ & $5(20 \%)$ & $4(16 \%)$ \\
Radical cystectomy & $3(12 \%)$ & $4(16 \%)$ & $5(20 \%)$ \\
Colectomy & $4(16 \%)$ & $3(12 \%)$ & $3(12 \%)$ \\
Ovariectomy & $4(16 \%)$ & $4(16 \%)$ & $2(8 \%)$ \\
Sigmoidetomy & $2(8 \%)$ & $2(8 \%)$ & $3(12 \%)$ \\
Trachilectomy & $2(8 \%)$ & $2(8 \%)$ & $2(8 \%)$ \\
Retroperitoneal mass & $2(8 \%)$ & $1(4 \%)$ & $2(8 \%)$ \\
Pelviabdominal mass & $0(0 \%)$ & $2(8 \%)$ & $2(8 \%)$ \\
Low anterior resection & $1(4 \%)$ & $1(4 \%)$ & $1(4 \%)$ \\
Pelvic abscess & $0(0 \%)$ & $1(4 \%)$ & $0(0 \%)$ \\
Staging laparotomy & $0(0 \%)$ & $0(0 \%)$ & $1(4 \%)$ \\
\hline
\end{tabular}

VAS score of pain was comparable in the three groups after 2, 4 and 12 hours post-operatively (Table 3). After 6 hours, VAS score was significantly higher in group TAP compared to group TAP + IV-Dex $(p=0.003)$. There was no significant difference between group TAP and group TAP + Dex $(p=0.149)$ and between group TAP + Dex and group TAP + IV-Dex $(p=0.595)$. After 24 hours, VAS score was significantly higher in group TAP compared to group TAP + IV-Dex $(p=0.020)$. There was no significant difference between group TAP and group TAP + Dex $(p=0.444)$ and between group TAP + Dex and group TAP + IV-Dex $(p=0.624)$. In group TAP, VAS score increased relative to the 2 hours reading after 6,12 and 24 hours $(p<0.001$ for all comparisons) Fig. (1).

Table (3): Visual Analogue Scale (VAS) score of pain during the first post-operative 24 hours in the three studied groups.

\begin{tabular}{lllll}
\hline & $\begin{array}{c}\text { TAP } \\
\mathrm{n}=25\end{array}$ & $\begin{array}{c}\text { TAP + Dex } \\
\mathrm{n}=25\end{array}$ & $\begin{array}{c}\text { TAP }+ \\
\text { IV-Dex } \\
\mathrm{n}=25\end{array}$ & $\begin{array}{c}p- \\
\text { value }\end{array}$ \\
\hline Post-operative 2 hours & $0(0-8)$ & $0(0-2)$ & $0(0-2)$ & 0.872 \\
Post-operative 4 hours & $2(0-4)$ & $0(0-5)$ & $0(0-2)$ & 0.213 \\
Post-operative 6 hours & $2(0-8)^{*}$ & $2(0-6)$ & $0(0-6)$ & 0.005 \\
Post-operative 12 hours & $4(0-8)^{*}$ & $2(0-9)^{*}$ & $3(0-8)$ & 0.376 \\
Post-operative 24 hours & $6(0-8)^{*}$ & $5(0-8)^{*}$ & $3(0-8)$ & 0.026 \\
\hline
\end{tabular}

Data are presented as median (range).

*: Significant change relative to the baseline reading.

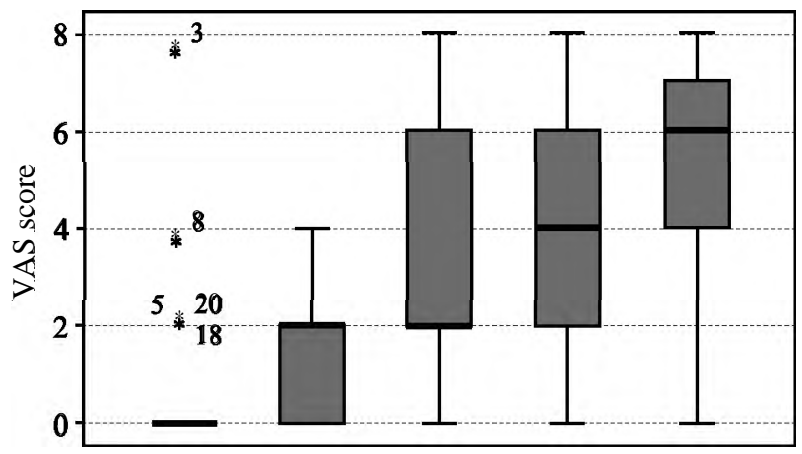

2 hours 4 hours 6 hours 12 hours 24 hours

Fig. (1): VAS score of pain during the first post-operative 24 hours in group TAP.

In group TAP + Dex, VAS score increased relative to the 2 hours reading after 12 and 24 hours ( $p=0.042$ and $p=0.002$ ) Fig. (2).

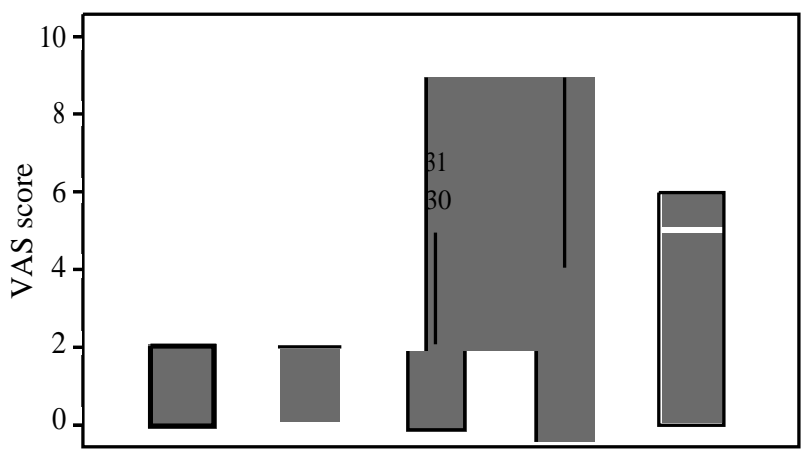

2 hours 4 hours 6 hours 12 hours 24 hours

Fig. (2): VAS score of pain during the first post-operative 24 hours in group TAP + Dex.

Similarly, in group TAP + IV-Dex, VAS score increased relative to the 2 hours reading after 12 and 24 hours ( $p=0.004$ and $p=0.015)$ Fig. (3). 


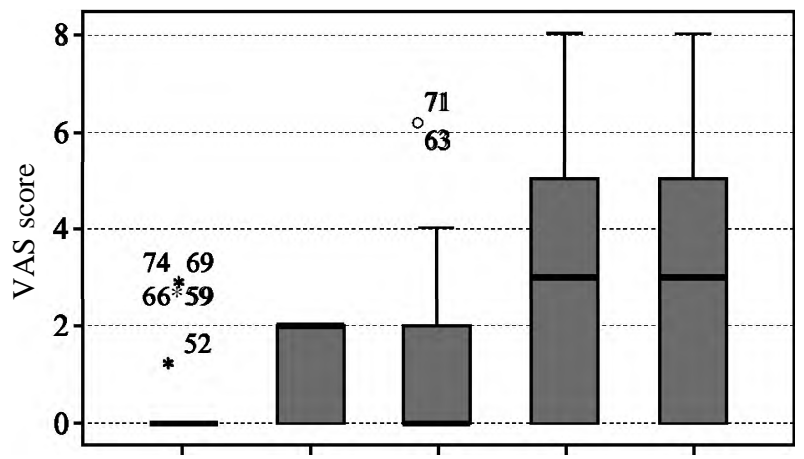

2 hours 4 hours 6 hours 12 hours 24 hours

Fig. (3): VAS score of pain during the first post-operative 24 hours in group TAP + IV Dex.

The time to first request of rescue analgesic was significantly shorter in group TAP compared to the other two groups $(p<0.001$ for the two comparisons) (Table 4). TAP + Dex and group TAP + IV-Dex had comparable time to first request of rescue analgesic $(p=1.000)$.

Similarly, the total morphine consumption during the first 24 hours was significantly higher in group TAP compared to the other two groups ( $p<$ 0.001 for the two comparisons) (Table 4). TAP + Dex and group TAP + IV-Dex had comparable morphine consumption $(p=1.000)$.

Table (4): Time to first request of rescue analgesic and total morphine consumption during the first postoperative 24 hours in the three studied groups.

\begin{tabular}{|c|c|c|c|c|}
\hline & $\begin{array}{c}\text { TAP } \\
n=25\end{array}$ & $\begin{array}{c}\text { TAP + } \\
\text { Dex } \\
n=25\end{array}$ & $\begin{array}{c}\text { TAP + } \\
\text { IV-Dex } \\
n=25\end{array}$ & $\begin{array}{c}p- \\
\text { value }\end{array}$ \\
\hline Time to first rescue (hours) & $5.7 \pm 1.6$ & $9.8 \pm 2.9$ & $10.0 \pm 2.3$ & $<0.001$ \\
\hline Total morphine $(\mathrm{mg})$ & $24.3 \pm 3.6$ & $11.8 \pm 3.7$ & $11.8 \pm 3.6$ & $<0.001$ \\
\hline
\end{tabular}

Data are presented as mean \pm SD.

There was no significant difference between the three groups in Post-operative Nausea and Vomiting (PONV) score (Table 5). The median score was 0 ranging from 0 to 3 in the three groups $(p=0.267)$.

Table (5): Post-operative Nausea and Vomiting (PONV) score in the three studied group.

\begin{tabular}{|c|c|c|c|}
\hline & $\begin{array}{l}\text { TAP } \\
n=25\end{array}$ & $\begin{array}{c}\mathrm{TAP}+\text { Dex } \\
\mathrm{n}=25\end{array}$ & $\begin{array}{c}\text { TAP + IV-Dex } \\
n=25\end{array}$ \\
\hline \multicolumn{4}{|c|}{ PONV score: } \\
\hline 0 & $13(52.0 \%)$ & $15(60.0 \%)$ & $18(72.0 \%)$ \\
\hline 1 & $5 \quad(20.0 \%)$ & $5 \quad(20.0 \%)$ & $4 \quad(16.0 \%)$ \\
\hline 2 & $3 \quad(12.0 \%)$ & $4 \quad(16.0 \%)$ & $2(8.0 \%)$ \\
\hline 3 & $4 \quad(16.0 \%)$ & $1 \quad(4.0 \%)$ & $1 \quad(4.0 \%)$ \\
\hline
\end{tabular}

Data are presented as number $(\%)$.

$p$-value cannot be computed due to the small number of cases in subgroups.
Patient Satisfaction (PS) score is shown in (Table 6) and figure 4. PS score was significantly lower in group TAP compared to the other two groups ( $p<0.001$ for the two comparisons). TAP + Dex and group TAP + IV-Dex had comparable PS scores $(p=1.000)$.

Table (6): Patient satisfaction score in the three studied groups.

$$
\begin{array}{cccc}
\text { TAP } & \text { TAP }+ & \text { TAP }+ & p \text { - } \\
\mathrm{n}=25 & \text { Dex } & \text { IV-Dex } & \text { value } \\
& \text { n=25 } & \text { n-25 } &
\end{array}
$$

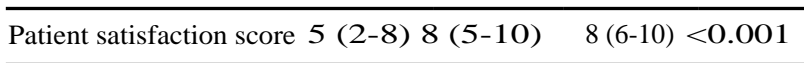

Data are presented as median (range).

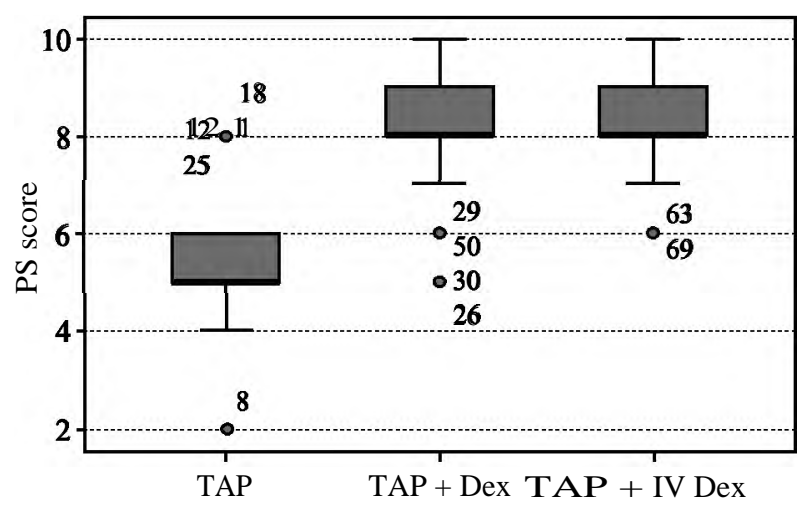

Fig. (4): Patient Satisfaction (PS) score in the three studied groups.

\section{Discussion}

Perioperative management of pain is the anesthesiologist's main concern, putting in consideration, using the method of pain control with the least side effects. Opioids remain the 'Gold Standard' drugs used for post-operative pain management where morphine is the most frequently used opioid in the perioperative setting [12] however opioids are not always easily tolerated and are associated with dose dependent side effects. Opioid related side effects can lead to delayed recovery and rehabilitation due to opioid perioperative complications as sedation, drowsiness, Post-operative Nausea and Vomiting (PONV), ileus, urinary retention, constipation, pruritis, and respiratory depression [13] .

There is evidence that the local anesthetic injected in the TAP using ultrasound guided posterior approach spreads to the quadratus lumborum and extends postromedially to the paravertebral space producing more extensive analgesia [14] Therefore, we used a volume of $30 \mathrm{ml}$ of injectate to increase its distribution within the TAP and increase the sensory block. 
When assessing postoperative VAS pain scores, we found that they were comparable at most times but were significantly higher in TAP group at $6 \mathrm{hrs}$ and $24 \mathrm{hrs}$ compared to TAP + IV-Dex ( $p=0.003$ and 0.20 , respectively). VAS scores in both groups that received dexmedetomidine increased at 12 hours post-operative relative to the 2 hours value whereas VAS scores increased at only 6 hours in TAP group. This indicates prolonged duration of analgesia in dexmedetomidine groups. The pronounced analgesia we achieved was attributed to the TAP block being a part of the multimodal regimen used.

We added paracetamol to our post-operative regimen to benefit from its central action. Paracetamol has antipyretic and analgesic actions; its antipyretic activity is through its inhibitory action on central COX-2 and COX-3 enzymes in the brain and spinal cord, while its analgesic effect seems to be due to activation of descending serotonergic inhibitory pathways and inhibition of central Nitric Oxide (NO) synthases. It is also believed to produce analgesia centrally as a cannabinoid agonist and by antagonizing NMDA and substance $\mathrm{P}$ in the spinal cord $[15,16]$.

A study comparing TAP block with ropivacaine vs. placebo for patients undergoing elective total abdominal hysterectomy showed that TAP block reduced post-operative VAS pain scores. Total morphine consumption was also reduced in the TAP block group to $55 \pm 17$ vs $27 \pm 20$ during the first 48 hours post-operative [17]. TAP block was also found to provide good analgesia to the skin and musculature of the anterior abdominal wall in patients undergoing various abdominal surgeries by other researchers $[\mathbf{1 8 , 1 9 ]}$. In another study done by McDonnell et al., [20], the authors contributed the prolonged effect of ropivacaine TAP block to the relatively poorly vascularized TAP resulting in a slower rate of drug clearance.

In our study, total morphine consumption during the first 24 hours $(\mathrm{mg}$ ) postoperative was significantly higher in TAP group compared to the other two groups ( $24.3 \pm 3.6$ vs. $11.8 \pm 3.6$ and $11.8 \pm 3.6$; $p<0.001)$. The relatively low total morphine requirement is explained by the prolonged action of TAP block and use of ketorlac as a rescue analgesic when VAS score was less than 5. Ketorolac is an injectable nonsteroidal anti-inflammatory drug (NSAID) with analgesic properties where NSAID's were found to be useful in reducing opioid requirement thus reducing opioid side effects [21]. However, there are some conditions in which ketorolac should be avoided as in patients suffering from ongoing or significant bleeding, coagulation disorders, quantitative or qualitative platelet dysfunction, renal or hepatic impairment, uncorrected hypovolemia or hypotension. It also should not be given in asthmatic patients [22,23]

In a study done by Sharma et al., [24], TAP block was performed after completion of abdominal surgery and compared to those who received only standard care including patient controlled tramadol analgesia (PCA). Results showed reduced postoperative pain scores in the TAP group. Patients who recieved TAP block had reduced tramadol requirement in 24 hours $(\mathrm{mg})(210.05 \pm 20.5$ vs. $320.05 \pm$ 10.6; $p<0.01$ ), and a longer time to the first PCA tramadol request (in minutes) compared to the control group (178.5 \pm 45.6 vs. $23.5 \pm 3.8 ; p<0.001)$.

In agreement with our results, a systematic review and meta-analysis evaluating the effects of TAP block in adults undergoing abdominal surgery showed that 24 hour morphine consumption was significantly reduced in patients who received a TAP block and the incidence of PONV was significantly reduced. The authors recommended that it should be considered as part of a multimodal approach to anesthesia and enhanced recovery in patients undergoing abdominal surgery [25]

Many adjuvants have been used to intensify the quality and increase the duration of different regional and peripheral nerve blocks. Dexmedetomidine is an $\alpha-2$ adrenergic agonist that prolongs analgesia when used in neuraxial and peripheral nerve blocks. $\alpha-2$ agonists are thought to improve the characteristics of local anesthetics through numerous possible mechanisms such as vasoconstriction, facilitation of the C-fiber blockade by the local anesthetic solution or by an action at the spinal cord level caused by slow retrograde axonal transport along the nerve [6]

This study focused on the effect of adding dexmedetomidine to TAP block on the duration of post-operative analgesia and opioid consumption. We found that the time to first request of rescue analgesia was significantly shorter in the TAP group compared to the other groups whether dexmedetmidine was given with the local anesthetic or IV $(p<0.001)$.

Brummett et al., [26] have presented that highdose dexmedetomidine added to bupivacaine improved local anaesthetic blockade in rats without exhibiting any neurotoxicity. Many studies have showed that the addition of dexmedetomidine to local anesthetic in central neuraxial blocks and in peripheral nerve blockades in human was a safe 
and effective way to potentiate the local anesthetic effect and reduce the required analgesics $[11,27,28]$

On the other hand, Ozalp et al., [29] compared dexmedetomidine-ropivacaine combination to ropivacaine alone in patient controlled interscalene analgesia and they stated similar pain scores in both groups without any beneficial effect of dexemedetomidine.

The main conclusion of a study performed by Almarakbi and Kaki, [30], was that addition of dexmedetomidine to bupivacaine in TAP block offers prolonged post-operative analgesia and better pain control than local anesthetic alone which comes in hand with our study. TAP block was performed in patients undergoing abdominal hysterectomy where patients were divided into two equal groups. The time to the first analgesic dose was longer and the total doses of used morphine were less in patients who received dexmedetomidine in comparison to local anesthetic alone [ $(470$ vs. $280 \mathrm{~min}, p<0.001)(19$ vs. $29 \mathrm{mg} / 24 \mathrm{~h}, p<0.001)$ respectively]. Moreover, VAS scores were significantly lower dexmedetomidine group in the first 8 hours post-operatively, both at rest and on coughing. Also lower heart rate values were noticed $60 \mathrm{~min}$ from the induction time and continued for the first $4 \mathrm{~h}$ post-operatively.

In contrast to our results, Aksu et al., [31] showed that when TAP block was done with bupivacaine + dexmedetomidine vs bupivacaine alone, VAS scores post-operatively were decreased significantly for 24 vs 8 hours only respectively. We believe that we did not achieve that length of analgesia due to the more extensive surgeries and tissue damage that occurs in radical oncological surgeries in our institute producing a higher intensity and additional visceral pain that the regular.

A study similar to ours examining the efficacy of IV and perineural dexmedetomidine in prolonging the analgesic duration of single-injection interscalene brachial plexus block (ISB) for outpatient shoulder surgery showed results that are comparable to our results. The authors concluded that both routes can effectively prolong the ISB analgesic duration and reduce the opioid consumption. The average duration of analgesia was $10.9 \mathrm{~h}$ and $9.8 \mathrm{~h}$ for the perineural dexmeditomidine (Dex P) and IV dexmedetomidine (Dex IV) groups, respectively, compared with $6.7 \mathrm{~h}$ for the control group. During the first post-operative $8 \mathrm{~h}$ interval, analgesic consumption was lower in the two groups that received dexmedetomidine being average of $13.9 \mathrm{mg}$ and
14. $1 \mathrm{mg}$ of morphine required by patients in the Dex P and Dex IV groups, respectively, compared with $23.3 \mathrm{mg}$ for the control group [32]

When the effect of perineural administration of dexmedetomidine in combination with bupivacaine in a femoral-sciatic nerve block in patients scheduled for below knee surgery was examined by Helal et al., they found that the addition of 100 daxmedetomidine to $0.5 \%$ bupivacaine in the block significantly prolonged duration of anesthesia compared to bupivacaine alone by $75 \%$ [33] .

Kubre et al., [34] found that a single dose intravenous dexmedetomine with spinal anesthesia, significantly prolonged the time to first request for post-operative analgesic $(234.67 \pm 7.649 \mathrm{~min})$ and the $24 \mathrm{~h}$ mean requirement of analgesics was significantly less compared to the control group. Similarly, Hong et al., 2012 [35] noticed that postoperative pain intensity was lower and the mean time to first request for postoperative analgesia was longer in the dexmedetomidine group compared to the control group (6.6 vs. 2. 1hrs).

Regarding PONV, the incidence of nausea and vomiting was not affected by the use of dexmeditomidine which is in agreement with the study done by Aksu et al., [31]. On the contrary, Chiruvella et al., [36] found a decreased incidence of $50 \%$ in PONV in patients receiving TAP block with dexmedetomidine than those who received just levobupivac aine .

When patient satisfaction scores were assessed we found that the use of dexmedetomidine with TAP block in patients undergoing abdominal surgery offered better level of satisfaction among the patients. Akin et al., compared postoperative analgesia, in patients undergoing abdominal surgery, using epidural with bupivacaine with or without dexmedetomidine infusion. In agreement with our results, the authors found that patient satisfaction was excellent in the dexmedetomidine group compared with the control group [37]

Aksu et al., [31] also found that patient satisfaction index was higher in patients who received TAP block with dexmedetomidine + bupivacaine than conventional TAP with just bupivacaine.

On the contrary, Kaur et al., did not find significant difference in patient satisfaction whether they added dexmedetomidine in the supraclavicular brachial plexus block or not in patients undergoing upper limb orthopedic surgery. They showed equally good satisfaction score in both groups [38] 


\section{Conclusion:}

The use of dexmedetomidine with TAP block as a part of multimodal analgesia proved to be an effective and safe technique to obtain prolonged post-operative analgesia and reduce total morphine requirements in cancer patients undergoing major pelvic and abdominal surgeries with no recorded adverse effects. It is recommended to further test its effect on a specific study group with same type of surgery and incision as we had variation in the sample we tested in our study.

\section{References}

1- WHITE P.F.: The changing role of non-opioid analgesic techniques in the management of post-operative pain. Anesth. Analg., 101 (5 Suppl): S5-S22, 2015.

2- RAFI A.N.: Abdominal field block: A new approach via the lumber tiangle. Anaesthesia, 56: 1024, 2001.

3- SIDDIQUI M.R., SAJID M.S., UNCLES D.R., CHEEK L. and BAIG M.K.: A meta-analysis on the clinical effectiveness of transversus abdominis plane block. Journal of Clinical Anesthesia, 23 (1): 7-14, 2011.

4- AVELINE C., Le HETET H., LE ROUX A., VAUTIER P., COGNET F., VINET E., et al.: Comparison between ultrasound-guided transversus abdominis plane and conventional ilioinguinal/iliohypogastric nerve blocks for day-case open inguinal hernia repair. Br. J. Anaesth., 106 (3): 380-6, 2011.

5- YAZBEK-KARAM V.G. and AOUAD M.M.: Perioperative uses of dexmeditomidine. M.E.J. Anaesth., 18: 10431056, 2006.

6- GREWAL A.: Dexmedetomidine: New Avenues. J. Anaesthesiol. Clin. Pharmacol., 27: 297-302, 2011.

7- YOSHOTOMI T., KOHJITANI A., MAEDA S., HIGUCHI, SHIMADA M. and MIYAWAKI T.: Dexmedetomidine enhances the local anesthetic action of lidocaine via an alpha-2A adrenoceptor. Anesth. Analog., 107: 96-101, 2008.

8- KHAN Z.P., FERGUSON C.N. and JONES R.M.: Alpha2 and imidazoline receptor agonists. Their pharmacologic and therapeutic role. Anaesthesia, 54: 146-65, 1999.

9- SHUKRY M. and MILLER J.A.: Update on dexmedetomidine: Use in nonintubated patients requiring sedation for surgical procedures. Ther. Clin. Risk Manag., 6: 111$21,2010$.

10- KAWAMATA M., ISHITANI K., ISHIKAWA K., et al.: A comparison between celiac plexus block and morphine treatment on quality of life in patients with pancreatic cancer pain. Pain, 64: 597-602, 1996.

11- GUPTA R., BOGRA J., VERMA R., KOHLI M., KUSHWAHA J.K. and KUMAR S.: Dexmedetomidine as an intrathecal adjuvant for post-operative analgesia. Indian J. Anaesth., 55 (4): 347-51, 2011.

12- BUJEDO B.M.: A Clinical Approach to Neuraxial Morphine for the Treatment of Post-operative Pain. Pain Research and Treatment, 2012: 612145, 2012.
13- VADIVELU N., MITRA S. and NARAYAN D.: Recent advances in post-operative pain management. Yale J. Biol. Med., 83: 11-25, 2010.

14- CARNEY J., FINNERTY O., RAUF J., BERGIN D., LAFFEY J.G. and Mc DONNELL J.G.: Studies on the spread of local anaesthetic solution in transversus abdominis plane blocks. Anaesthesia, 66 (11): 1023-30, 2011.

15- BERTOLINI A., FERRARI A., OTTANI A., et al.: Paracetamol: New vistas of an old drug. C.N.S. Drug Rev., 12: 250-75, 2006.

16- GRAHAM G.G. and SCOTT K.F.: Mechanism of action of paracetamol. Am. J. Ther., 12: 46-55, 2005.

17- CARNEY J., MCDONNELL J.G., OCHANA A., BHINDER R. and LAFFEY J.G.: The transversus abdominis plane block provides effective post-operative analgesia in patients undergoing total abdominal hysterectomy, Anesth. Analg., 107 (6): 2056-60, 2008.

18- O'DONNELL B.D., McDONNELL J.G. and McSHANE A.J.: The transversusabdominis plane (TAP) block in open retropubic prostatectomy. Reg. Anesth. Pain. Med., 31: 91, 2006.

19- MCDONNELL J.G., O'DONNELL B., CURLY G., HEFFERNAN A., POWER C. and LAFFEY J.G.: The analgesic efficacy of transverses abdominis plane block after abdominal surgery: A prospective randomized controlled trial. Anesth. Analog., 104: 193-7, 2007.

20- McDONNELL J.G., CURLEY G., CARNEY J., BENTON A., COSTELLO J., MAHARAJ C.H., et al.: The analgesic efficacy of transversusabdominis plane block after cesarean delivery: A randomized controlled trial. Anesth. Analg., 106: 186-91, 2008

21- GARIMELLA V. and CELLINI C.: Post-operative Pain Control. Clinics in Colon and Rectal Surgery, 26 (3): 1916, 2013.

22- TOBIAS J.D. : Weak analgesics and non steroidal antiinflammatory agents in the management of children with acute pain. Pediatr. Clin. North Am., 47: 527-43, 2000.

23- KOKKI H.: Nonsteroidal anti-inflammatory drugs for post-operative pain: A focus on children. Paediatr. Drugs, 5: 103-23, 2003.

24- SHARMA P., CHAND T. , SAXENA A., BANSAL R., MITTAL A. and SHRIVASTAVA U.: Evaluation of postoperative analgesic efficacy of transversus abdominis plane block after abdominal surgery: A comparative study. Journal of Natural Science, Biology, and Medicine, 4 (1): 177-80, 2013.

25- JOHNS N., O'NEILL S., VENTHAM N.T., BARRON F., et al.: Clinical effectiveness of transversus abdominis plane (TAP) block in abdominal surgery: A systematic review and meta-analysis. Colorectal. Dis., 14 (10): 63542, 2012.

26- BRUMMETT C.M., NORAT M.A., PALMISANO J.M. and LYDIC R.: Perineural administration of dexmedetomidine in combination with bupivacaine enhances sensory and motor blockade insciatic nerve block without inducing neurotoxicity in rat. Anesthesiology, 109: 502-11, 2008.

27- KANAZI G.E., AOUAD M.T., JABBOUR KHOURY S.I., et al.: Effect of low-dose dexmedetomidine or cloni- 
dine on the characteristics of bupivacaine spinal block. Acta Anaesthesiol. Scand., 50: 222-7, 2006.

28- JAIN D., KHAN R.M., KUMAR D. and KUMAR N.: Perioperative effect of epidural dexmedetomidinewith intrathecal bupivacaine on haemodynamic parameters and quality of analgesia. South Afr. J. Anaesth. Analg., 18: 105-9, 2012.

29- OZALP G., TUNCEL G., SAVLI S., CELIK A., DOGER C., KAYA M., et al.: The analgesic efficacy of dexmedetomidine added to ropivacaine patient controlled inte4rscalene analgesia via the posterior approach. J. Anaesth., 21: 409-12, 2006.

30- ALMARAKBI W.A. and KAKI A.M.: Addition of dexmedetomidine to bupivacaine in transversus abdominis plane block potentiates post-operative pain relief among abdominal hysterectomy patients: A prospective randomized controlled trial. Saudi Journal of Anaesthesia, 8 (2): 1616, 2014.

31- AKSU R., PALMANO G., BIÇER C., EMEK E. and ÇORUH A.E.: Efficiency of bupivacaine and association with dexmedetomidine in transversus abdominis block ultrasound guided in post-operative pain of abdominal surgery. Rev. Bras. Anestesiol., 2017.

32- ABDALLAH F.W., DWYER T., CHAN V.W., NIAZ A.U., et al.: IV and Perineural Dexmedetomidine Similarly Prolong the Duration of Analgesia after Interscalene Brachial Plexus Block: A Randomized, Three-arm, Triplemasked, Placebo-controlled Trial. Anesthesiology, 124 (3): 683-95, 2016.
33- HELAL S.M., ESKANDR A.M., GABALLAH K.M. and GAAROUR I.S.: Effects of perineural administration of dexmedetomidine in combination with bupivacaine in a femoral-sciatic nerve block. Saudi Journal of Anaesthesia. 10 (1): 18-24, 2016.

34- KUBRE J., SETHI A., MAHOBIA M., BINDAL D., NARANG N. and SAXENA A.: Single dose intravenous dexmedetomidine prolongs spinal anesthesia with hyperbaric bupivacaine. Anesth. Essays. Res., 10: 273-7, 2016.

35- HONG J.Y., KIM W.O., YOON Y., CHOI Y., KIM S.H. and KIL H.K.: Effects of intravenous dexmedetomidine on low-dose bupivacaine spinal anaesthesia in elderly patients. Acta Anaesthesiol. Scand., 56: 382-7, 2012.

36- CHIRUVELLA S., DONTU B. and SIVA V.: Effect of dexmedetomidine with levobupivacaine on duration of transversus abdominis plane blocks compared to levobupivacaine with normal saline: A prospective, randomized and double blind study. I.J.S.A.R., 2 (2): 01-07, 2015.

37- AKIN S., ARIBOGAN A. and ARSLAN G.: Dexmedetomidine as an adjunct to epidural analgesia after abdominal surgery in elderly intensive care patients: A prospective, double-blind, clinical trial. Curr. Ther. Res., 69: 16-28, 2008.

38- KAUR H., SINGH G., RANI S., et al.: Effect of dexmedetomidine as an adjuvant to levobupivacaine in supraclavicular brachial plexus block: A randomized doubleblind prospective study. Journal of Anaesthesiology, Clinical Pharmacology, 31 (3): 333-8, 2015.

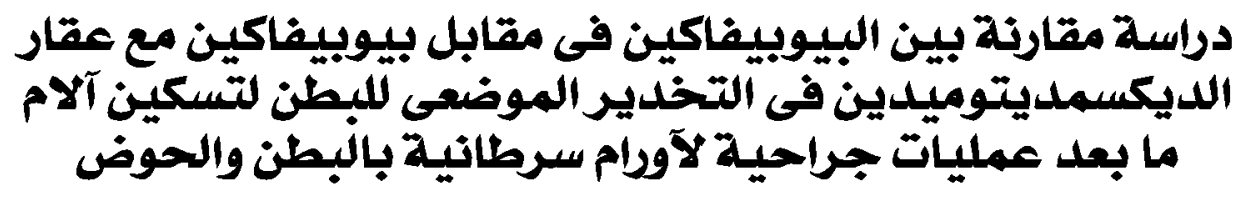

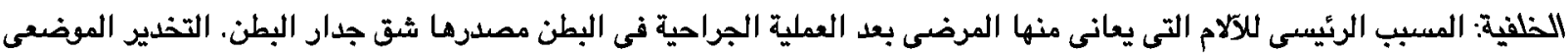

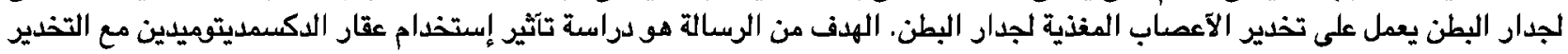

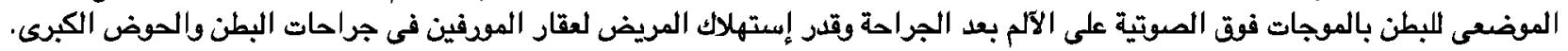

الآساليب: تم إختيار خمس وبسعون مريضا عشوائيا فى هذه الدراسة وتم تقسيمه إلى ثلاث مجموعات: مجموعة البيوبيفاكين (مجموعة

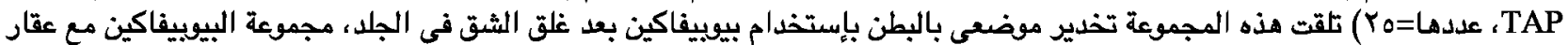

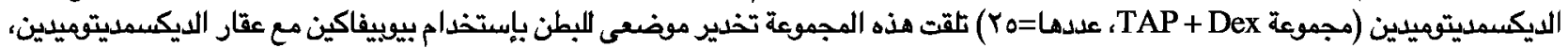

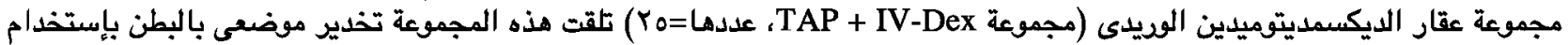

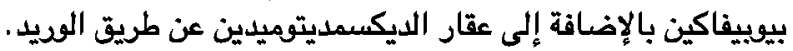

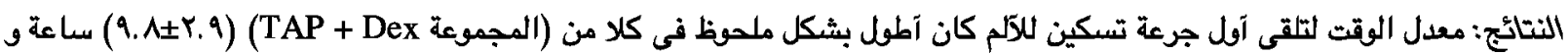
Y (المجموعة TAP + Dex-IV)

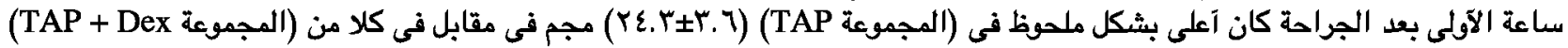

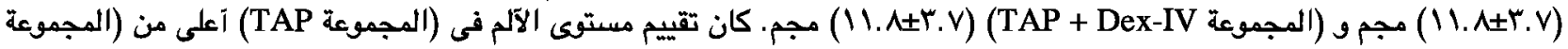
(TAP + IV-Dex بشكل ملحوظ (المجموعة TAP) مقارنة بالمجموعتين الآخرى.

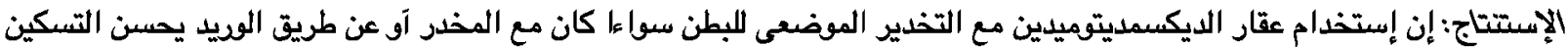

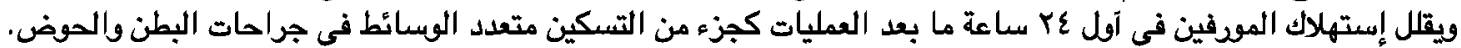

